\title{
Kegiatan Eksplorasi untuk Meningkatkan Kreativitas Anak Usia Dini di TK Islam Baiturrahim Jambi
}

\author{
Wanti Hasmar ${ }^{1}$, Indah Permata Sari ${ }^{2}$, Mawaddah Warahmah ${ }^{3}$ \\ 1,2,3 Program Studi D III Fisioterapi, STIKes Baiturrahim Jambi \\ e-mail: wanti.cemar@gmail.com
}

Submitted : 22/07/2021

Accepted: 19/10/2021

Published: 17/11/2021

\begin{abstract}
Exploration is looking for or doing exploration with the aim of finding something. Considering that early childhood does not need theory intake, the learning process is designed using practical activities in the surrounding environment through exploration activities. The teacher's job is only as a companion and facilitator. Community service activities will be carried out in May-June 2021 with the method of discussion and delivering materials and leaflets related to the education of kindergarten children's exploration activities. The leaflet consists of 3 activities, namely water play activities, sand play and gardening activities. This Community Service (PKM) aims to be used as a source of knowledge for parents of children in Baiturrahim Islamic Kindergarten Jambi. The results of the evaluation through the question and answer are that on average the parents of kindergarten children understand and can implement exploration activities in order to increase the creativity of kindergarten children.
\end{abstract}

Keywords : creativity, exploration, early childhood

\begin{abstract}
Abstrak
Eksplorasi adalah mencari atau melakukan penjelajahan dengan tujuan menemukan sesuatu. Mengingat anak usia dini tidak membutuhkan asupan teori, maka proses pembelajaran didesain menggunakan kegiatan praktik pada lingkungan sekitar melalui kegiatan eksplorasi. Tugas guru hanyalah sebagai pendamping dan fasilitator. Kegiatan Pengabdian masyarakat dilaksanakan pada bulan mei-juni 2021 dengan metode diskusi dan menyampaikan materi serta leaflet terkait edukasi kegiatan eksplorasi anak TK. Leaflet terdiri dari 3 kegiatan yaitu kegiatan bermain air, bermain pasir dan kegiatan berkebun. Pengabdian kepada Masyarakat (PKM) ini bertujuan untuk dapat dijadikan sebagai sumber pengetahuan bagi orang tua anak di TK Islam baiturrahim jambi. Hasil evaluasi melalui tanya jawab tersebut adalah rata-rata orang tua anak TK memahami dan dapat menerapkan kegiatan eksplorasi agar dapat meningkatkan kreativitas anak TK.
\end{abstract}

Kata kunci : anak usia dini, eksplorasi, kreativitas

\section{PENDAHULUAN}

Taman kanak-kanak merupakan salah satu bentuk pendidikan prasekolah yang ada di jalur pendidikan sekolah. Pendidikan prasekolah adalah pendidikan untuk membantu pertumbuhan dan perkembangan, jasmani dan rohani anak di luar lingkungan keluarga sebelum memasuki Pendidikan Dasar. Usaha ini dilakukan supaya anak usia 4-6 tahun lebih siap mengikuti pendidikan selanjutnya. Adapun tujuan dari pada program kegiatan belajar anak taman kanak-kanak adalah untuk membantu meletakkan dasar ke arah perkembangan sikap, pengetahuan, keterampilan, dan daya cipta yang diperlukan oleh anak didik dalam menyesuaikan diri dengan lingkungannya dan untuk pertumbuhan dan perkembangan selanjutnya. Selanjutnya, sebagaimana terdapat dalam Garis-garis Besar Program Kegiatan Belajar Taman Kanak-kanak (Kemendikbud, 1994), taman kanak-kanak didirikan sebagai usaha mengembangkan seluruh segi kepribadian anak didik dalam rangka menjembatani pendidikan dalam keluarga dan pendidikan sekolah (Rachmawati Yeni dan Kurniati Euis, 2017). Namun pada pelaksanaannya, pembelajaran cenderung bersifat 
"akademik", lebih menekankan pada kemampuan kognitifnya. Semiawan Conny (2002) mengatakan bahwa prestasi belajar anak tidak hanya ditentukan oleh kemampuan intelektual yang bersifat kognitif nemun dipengaruhi pula oleh faktor non-kognitif. Faktof non-kognitif seperti emosi, motivasi, kepribadian dan faktor lingkungan.

Masa kanak-kanak adalah masa yang peka untuk menerima berbagai macam rangsangan dari lingkungan guna menunjang perkembangan jasmani dan rohani yang ikut menentukan keberhasilan anak didik mengikuti pendidikannya di kemudian hari. Masa kanak-kanak dapat juga dikatakan masa bermain, oleh sebab itu kegiatan pendidikan di taman kanakkanak diberikan melalui bermain sambil belajar, dan belajar sambil bermain. Dengan demikian, guru dituntut untuk memahami konsep dan aplikasi pengembangan kreativitas agar anak dapat tumbuh dan berkembang sesuai dengan potensi yang mereka miliki secara optimal.

Kreativitas merupakan salah satu bagian dari seluruh perkembangan manusia, oleh karena itu faktor yang mempengaruhi perkembangan manusia secara keseluruhan juga secara umum berpengaruh terhadap perkembangan kreativitas individu, meskipun secara spesifik ada penekananpenekanan tertentu pada setiap aspek perkembangan. Salah satu faktor yang mempengaruhi perkembangan kreativitas anak adalah faktor lingkungan, baik lingkungan fisik maupun sosial, baik keluarga, sekolah maupun masyarakat (Hawadi, 2001).

$$
\text { Lingkungan yang mampu }
$$

memberikan stimulasi terhadap potensi kecerdasan anak dengan baik, dalam suasana kondusif dan menyenangkan akan membantu perkembangan kreativitas anak. Terutama lingkungan sekolah, pihak internal sekolah khususnya guru harus mampu menyajikan kegiatan pembelajaran yang menarik dan menyenangkan untuk anak.

Kreativitas pada anak-anak memiliki ciri tersendiri, tidak dapat disamakan dengan kreativitas orang dewasa. Kreativitas anak dikoridori oleh keunikan gagasan dan tumbuhnya imajinasi serta fantasi. Anak-anak yang kreatif akan sensitif terhadap stimulasi. Mereka juga tidak dibatasi oleh frame-frame apapun.

Bagi anak usia kanak-kanak, mereka dikatakan kreatif ketika ia menemukan pemecahan atas permasalahan yang dihadapi. Mereka akan mempertimbangkan berbagai hal untuk memilih solusi terbaiknya. Kemudian, jika anak telah berhasil menyelesaikan masalahnya, maka ia disebut kreatif. Seperti contoh, ketika layang-layang seorang anak tersangkut di pohon. Maka ia akan mempertimbangkan cara, bagaimana supaya layang-layang yang diambil tidak sobek/rusak. Apakah akan mengunduhnya menggunakan kayu, memanjat, atau menarik-narik talinya. Begitulah anak-anak yang kreatif, mereka selalu menggunakan imajinasi ketika hendak bertindak.

Kegiatan eksplorasi ini sebagai pengganti kegiatan pembelajaran dan disesuaikan dengan tema pembelajaran. Misalnya, tema pembelajarannya adalah berkebun. Maka anak-anak akan diarahkan ke kebun, mengamati orang-orang berkebun kemudian membantu dan menirukan petani berkebun. Jika temanya adalah bangunan, maka anak akan diarahkan ke halaman yang disediakan pasir beserta berbagai bentuk cetakan, ember kecil, sekop, dan lainnya. Dengan bekal gambar beberapa bagunan dari buku, anak dituntun untuk memilih cetakan bangunan yang sesuai dengan gambar kemudian bermain pasir dan membuat cetakan bangunan sesuai dengan yang mereka inginkan.

Tugas guru hanyalah sebagai pendamping dan fasilitator. Guru mendampingi anak sekaligus memberikan pemahaman terkait dengan tema eksplorasi 
hari itu. Siswa diberikan kebebasan berekspresi dan berekspolrasi, meskipun harus basah-basahan dengan air dan kotor oleh tanah, namun kondisi tersebut merupakan bagian dari latihan motorik kasar dan halus anak. Guru tidak dianjurkan melarang ataupun memberikan batasan dari ekspresi dan gerak anak ((Rachmawati dan Kurniati, 2017).

Selain itu, kegiatan pembelajaran dengan alam juga dapat menstimulasi imajinasi anak agar terus berkembang. Berbeda jika pembelajaran hanya berpusat di dalam kelas, desain pembelajaran yang monoton dan kurang kreatif, secara otomatis kreativitas anak juga akan tumpul dan matilah imajinasi anak. Pada proses kegiatan eksplorasi, tidak ada perbedaan perlakuan kepada anak-anak. Guru menganggap semua anak memiliki kelebihan dan kekurangan. Jika anak dianggap lebih menonjol dari pada teman lainnya, maka ia diminta membantu temannya yang kesulitan. Seperti ketika anak bingung membedakan gambar burung dan kupu-kupu, teman lainnya membantu dan menuntun temannya untuk mencari gambar yang sama persis dengan hewan yang ia pegang, seperti burung.

Selain melatih perkembangan imajinasi dan kreativitas anak, nilai kerjasama teraplikasi di dalamnya. Bentuk kegiatan Eksplorasi sebagai upaya pengembangan kreativitas anak-anak. Dalam pelaksanaan kegiatan-kegiatan ekplorasi, guru menyesuaikan dengan tematema yang diajarkan pada setiap harinya.

Taman kanak-kanak merupakan salah satu bentuk pendidikan prasekolah yang memfasilitasi anak untuk membantu pertumbuhan dan perkembangan jasmani dan rohani anak, dan untuk membantu anak agar lebih siap mengikuti pendidikan selanjutnya. TK Islam Baiturrahim Jambi mempunyai banyak fasilitas dan kegiatan eksplorasi gerak yang dapat meningkatkan kreativitas anak-anak usia dini.
Metode yang digunakan adalah penjelasan kepada orang tua/wali anak menggunakan media leaflet mengenai edukasi kegiatan eksplorasi anak untuk meningkatkan kretavitas anak di TK Islam Baiturrahim Jambi kemudian orang tua anak memberikan respon. Hasil diskusi yang diharapkan pada pelaksanaan pengabdian masyarakat ini adalah agar orangtua memahami pentingnya kegiatan eksplorasi anak agar dapat meningkatkan kreativitas anak. Kegiatan pengabdian masyarakat ini diawali dengan survei untuk mengetahui bagaimana tingkat pengetahuan orang tua anak di TK Islama Baiturrahim Jambi.

\section{TARGET DAN LUARAN}

Target luaran Pengabdian masyarakat ini adalah dengan melakukan sosialisasi dan edukasi eksplorasi anak agar dapat meningkatkan kreativitas anak di TK Islam Baiturrahim Jambi, dengan harapan dapat dijadikan sebagai sumber pengetahuan bagi orang tua / wali anak dan dapat melakukan kegiatan eksplorasi anak di rumah. Di dalam leaflet ini terdapat 3 kegiatan eksplorasi anak, yaitu kegiatan bermain air, kegiatan bermain pasir dan kegiatan berkebun.

\section{METODE PELAKSANAAN}

Kegiatan Pengabdian masyarakat dilaksanakan pada Bulan Mei-juni 2021 dengan sasaran orang tua anak TK Islam Baiturrahim Jambi. Kegiatan Pengabdian Kepada Masyarakat (PKM) ini bertujuan untuk meningkatkan pengetahuan orang tua anak dan dapat menerapkan kegiatan tersebut dirumah agar dapat menigkatkan kreativitas anak

Kegiatan pengabdian masyarakat ini diharapkan dapat meningkatnya pengetahuan orang tua anak dalam kegiatan eksplorasi anak dan dapat menerapkan kegiatan tersebut. 


\section{Pelaksanaan Kegiatan}

Tahap pelaksanaan kegiatan pengabdian kepada masyarakat ini adalah sebagai berikut :

\section{Persiapan}

Tahapan ini merupakan tahapan awal dari pelaksanan Pengabdian Masyarakat, sebelumnya tim pengabdian masyarakat melakukan survey dengan cara berdiskusi denga salah satu orang tua anak di TK Islam Baiturrahim Jambi, setelah itu mengirimkan surat berupa perizinan dari Kepala TK Islam Baiturrahim Jambi pada bulan Mei 2021. Setelah mendapat izin, selanjutnya Tim Pengabdian Masyarakat melaksanakan sedikit diskusi kembali dengan salah satu siswa SMA 6 Merangin terkait Pengabdian Masyarakat yang akan dilaksanakan . Diskusi berlangsung dengan menggunakan aplikasi Zoom Meeting.

Tahap berikutmya dalam pesiapan pengabdian masyarakat ini adalah perancangan Materi dan pembuatan poster bergambar gambaran mengenai kasus tension headache dan cara stretching cervical. Sebelum menyampaikan Poster bergambar Tim Pengabdian Masyarakat menyampaikan materi terkait dengan kasus tension headache yaitu :Pengertian, etiologi, patofisiologi, cara stretching cervical. Selanjutnya mengirim Poster ini berisi tentang latihan stretching cervical.

Adapun Metode kegiatan diskusi selama pengabdian masyarakat pada siswa SMA 6 Merangin dengan mengirim materi dan poster bergambar yang terkait dengan stretching cervical.

\section{Pelaksanaan}

Pada tahap ini mulai dilakukan sosialisasi dan edukasi terkait stretching cervical dengan poster bergambar melalui online dengan aplikasi Zoom Meeting, materi power point mengenai kasus tension headache dan poster stretching cervical di jelaskan kepada siswa SMA 6
Merangin, kemudian dilakukan diskusi/ Tanya jawab.

\section{Monitoring dan Evaluasi}

Monitoring dan evaluasi (Monev) dilakukan secara langsung kepada sasaran. Cakupan Monev dalam kegiatan ini meliputi monev perencanaan dan pelaksanaan dan evaluasi hasil.

Monitoring dan evaluasi dilakukan dengan diskusi Tanya jawab. Evaluasi ini bertujuan untuk mengetahui sejauh mana respon dan peningkatan pemahaman serta pengetahuan masyarakat terkait Pengabdian Masyarakat yang sudah dilaksanakan. Cakupan monev dalam kegiatan ini meliputi empat aspek, yaitu sebagai berikut .

Cakupan Monev dalam kegiatan ini meliputi monev perencanaan dan pelaksanaan dan evaluasi hasil

Hasil evaluasi baik melalui tanya jawab adalah rata-rata orang tua anak mengetahui dan dapat mempraktekkan kegiatan eksplorasi anak di rumah dengan tujuan untuk meningkatkan kreativitas anak.

\section{HASIL DAN PEMBAHASAN}

Edukasi atau yang sering juga disebut Pendidikan merupakan segala upaya yang direncanakan untuk mempengaruhi orang lain baik individu, kelompok maupun mayarakat sehingga melakukan apa yang diharapkan oleh pelaku Pendidikan. Dalam kamus besar Bahasa Indonesia (KBBI) Pendidikan berasal dari kata dasar didik (mendidik), yaitu memelihara dan memberi latihan (ajaran pimpinan) mengenai akhlak dan kecerdasan pikiran.

Kegiatan Pengabdian masyarakat ini mengangkat tema "Edukasi kegiatan eksplorasi anak untuk meningkatkan kretivitas anak di TK Islam Baiturrahim Jambi pada bulan Juni 2021 yang sasarannya adalah orang tau anak TK Islam Baiturrahi Jambi. Pengabdian masyarakat ini dilakukan oleh 3 orang 
orang tim dosen dari program studi D-III Fisioterapi dan dibantu oleh Mahasiswa/mahasiswi Program Studi D3 Fisioterapi STIKes Baiturrahim Jambi, dihadiri oleh orang tua anak TK Islam Baiturrahim Jambi.

Adapun Kegiatan yang telah dilakukan adalah menyampaikan materi dan leaflet mengenai kegiatan eksplorasi anak yang bertujuan untuk meningkatkan kreativitas anak.

Kegiatan eksplorasi ini sebagai pengganti kegiatan pembelajaran dan disesuaikan dengan tema pembelajaran. Misalnya, tema pembelajarannya adalah berkebun. Maka anak-anak akan diarahkan ke kebun, mengamati orangorang berkebun kemudian membantu dan menirukan petani berkebun. Jika temanya adalah bangunan, maka anak akan diarahkan ke halaman yang disediakan pasir beserta berbagai bentuk cetakan, ember kecil, sekop, dan lainnya. Dengan bekal gambar beberapa bagunan dari buku, anak dituntun untuk memilih cetakan bangunan yang sesuai dengan gambar kemudian bermain pasir dan membuat cetakan bangunan sesuai dengan yang mereka inginkan (Rachmawati dan Kurniati, 2017).

Tugas guru hanyalah sebagai pendamping dan fasilitator. Guru mendampingi anak sekaligus memberikan pemahaman terkait dengan tema eksplorasi hari itu. Siswa diberikan kebebasan berekspresi dan berekspolrasi, meskipun harus basah-basahan dengan air dan kotor oleh tanah, namun kondisi tersebut merupakan bagian dari latihan motorik kasar dan halus anak. Guru tidak dianjurkan melarang ataupun memberikan batasan dari ekspresi dan gerak anak (Rachmawati dan Kurniati, 2017).

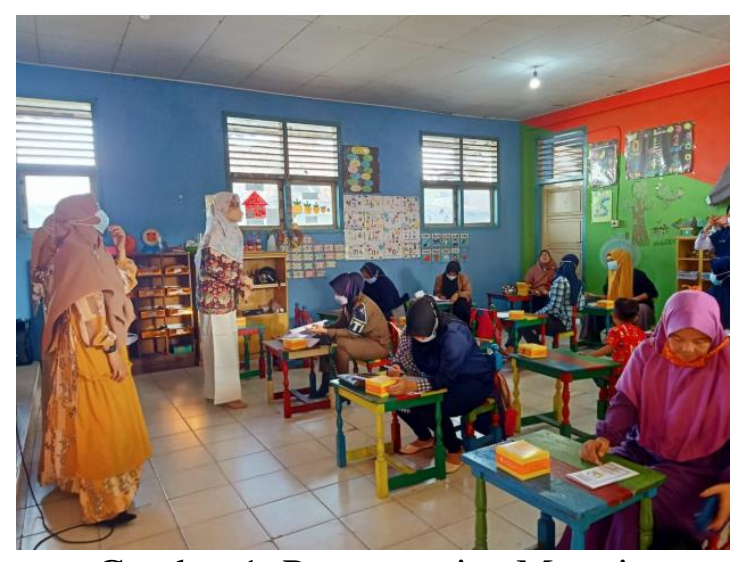

Gambar 1. Penyampaian Materi

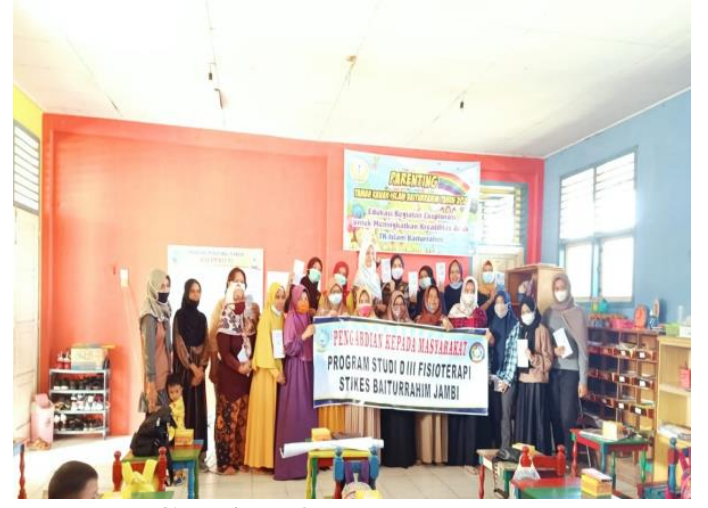

Gambar 3. Foto Bersama

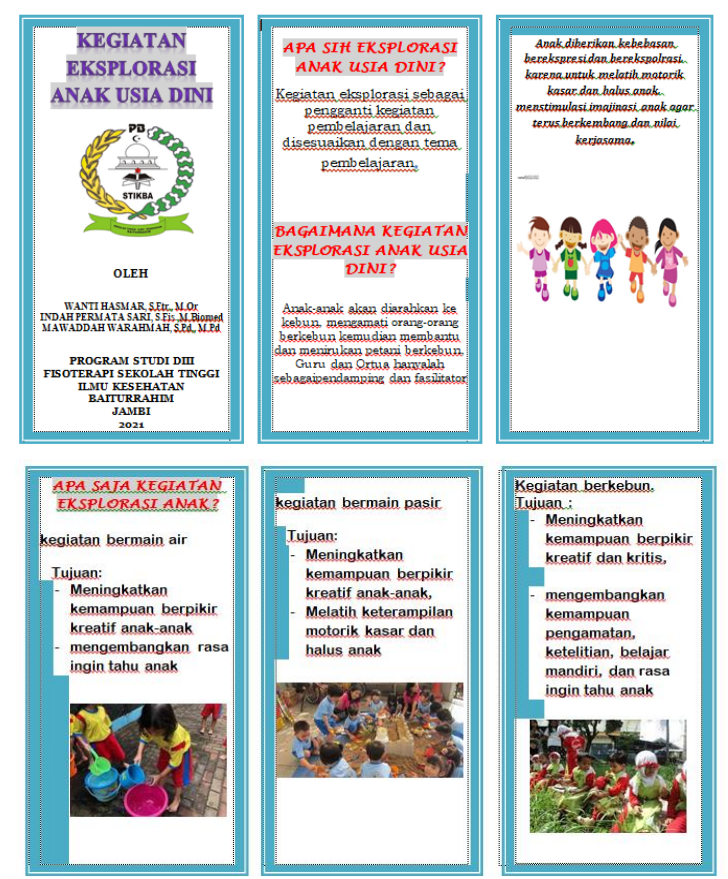

Gambar 4. Leaflet Kegiatan Eksplorasi Anak TK 


\section{KESIMPULAN DAN SARAN}

1. Kesimpulan

Setelah tim melaksanakan kegiatan pengabdian masyarakat pada Orang tua anak TK Islam Baiturrahim Jambi dapat memahami dan menerapkan kegiatan eksplorasi tersebut di rumah bersama anak

2. Saran

Hendaknya edukasi kegiatan eksplorasi anak ini dapat terus dilaksanakan di TK Islam Baiturrahim Jambi agar dapat memberikan pengetahuan pada orang tua anak TK mengenai edukasi kegiatan eksplorasi anak untuk meningkatakn kreativitas anak.

\section{UCAPAN TERIMAKASIH}

Tim Pengabdian mengucapkan terimakasih kepada STIKes Baiturrahim
Jambi atas dukungan moril serta materil sehingga kegiatan ini dapat terlaksana dengan baik.

\section{DAFTAR PUSTAKA}

Hawadi, R. A. (2001). Kreativitas. Jakarta: PT. Grasindo.

Kemendikbud. (1994). Garis-garis Besar Program Kegiatan Belajar Taman Kanak-kanak. Jakarta: Departemen Pendidikan dan Kebudayaan.

Rachmawati Yeni dan Kurniati Euis. (2017). Strategi Pengembangan Kreativitas Pada Anak, Usia Taman Kanak-kanak. Jakarta: Kencana Prenada Media Group.

Semiawan Conny. (2002). Belajar dan Pembelajaran Pada Taraf Anak Usia Dini. Jakarta: PT Prenhallindo 